Original Research Paper

\title{
A Note on the Renovation of Social Enterprise in Korea: Current Status and Future Prospects
}

\author{
Seok Yoon and Yoon-Doo Kim \\ Department of International Trade and Culture, College of International Business, \\ Konkuk University, 322 Danwol-Dong, Chungju-Si, Chungcheonbuk-Do, 380-701, Korea
}

\author{
Article history \\ Received: 15-09-2015 \\ Revised: $17-05-2016$ \\ Accepted: 18-05-2016 \\ Corresponding Author: \\ Yoon-Doo Kim \\ Department of International \\ Trade and Culture, College of \\ International Business, Konkuk \\ University, 322 Danwol-Dong, \\ Chungju-Si, Chungcheonbuk- \\ Do, 380-701, Korea \\ Email: ifvma@hanmail.net
}

\begin{abstract}
Social enterprise activities in Korea began after 1998. Korea was facing the IMF Financial Crisis which yielded growing unemployment and slow economic growth. The government, therefore, carried out the Social Job Creation Project for the unemployed on a trial basis as ways to provide jobs to the vulnerable. Since 2004, it has become a government-wide project. Moreover in 2007, the Korean government implemented the Social Enterprise Promotion Act. Unlike those in Europe and the U.S., this system did not come to fruition from the spontaneous necessity of a social enterprise in the market, but rather came into effect in line with government-led policy objectives such as job creation to solve market dysfunctionality. In Korea, social enterprise policies were intended to incubate social enterprises through the government's unique certification systems as well as various support systems. Further, in the eight years since the implementation, it has brought about remarkable policy effects. Thus, this paper, aims to look into the present condition and issues of social enterprises which regard these policy effects as Social Enterprise Renovation and whose policies have brought significant effects in a short period of time, as well as into policy issues for the development of sustainable social enterprises. In conclusion, to see social enterprises develop sustainably, First of all, direct support methods for labor costs are improved. Second, the indirect support is expanded for self-sustaining independence. Third, the linkage and collaboration between private and community are established. This refers to establishing the economic order to realize the goal of social enterprises-the pursuit of private profits and public interests-through the social enterprises nurtured up to the present standing on fair market competitiveness.
\end{abstract}

Keywords: Social Enterprise, Social Enterprise Certification, Renovation, Social Entrepreneurs, Social Entrepreneurship, South Korea

\section{Introduction}

Social enterprises began in Europe and then expanded into the U.S. and Japan. In addition, the development of social enterprises takes various forms, according to each country's history and socio-economic characteristics. Thereby, a general definition of a social enterprise differs from country to country, depending on the institutional characteristics. According to the OECD definition of an emerging social enterprise, it is a group organized around entrepreneurship, in pursuit of all socio-economic objectives (OECD, 1997).

It was around this time that social enterprise activities began in Korea. Korea was facing so-called IMF
Financial Crisis at that time and since then the country had growing unemployment caused by financial crisis, while showing a gradual decline in job creation ability due to changes to the industrial structure and slow economic growth. This consequently led to an increase in the vulnerable, such as the long-term unemployed, the self-employed and irregular workers.

The government, therefore, carried out the Social Job Creation Project by the Ministry of Employment and Labor in 2003 for the unemployed on a trial basis as ways to provide jobs to the vulnerable as well as expand social services. The project has gone government-wide since 2004. Due to indication and criticism that the government-led social job creation project only creates 
short-term temporary and low-wage jobs, there arose a necessity of a social enterprise as a model for providing sustainable quality jobs and social services.

The Korean government is implementing (July 1, 2007) Social Enterprise Promotion Act to institutionalize social enterprises and incubate them systematically. Unlike Europe and the U.S., this system characteristically did not appear upon the spontaneous necessity of a social enterprise in the market, but came into effect in line with government-led policy objectives such as job creation to solve a side effect of market. That is, this system is designed to set up a model that can create profits and seek independence through social job projects by means of certification programs for social enterprises. This system made remarkable achievements in a short period of time.

In addition, social enterprise policies have achieved rapid development because of government-supported facility costs, supporting labor costs, tax benefits, social insurance fees and management support, by creating stable jobs utilizing the third sector such as not-for-profit government corporation and organization and certifying organizations or businesses that provide social services as a social enterprise.

Social enterprise policies in Korea were intended to incubate social enterprises through the government's unique certification systems that were different from advanced countries as well as various government support systems. Social enterprise policies implemented following the IMF financial crisis in Korea resulted in significant effects in policy. Experts make a caution prediction that these effects of policy are regarded as a Renovation of Social Enterprise and such a revolution would make contributions to new entrepreneurship and corporate culture establishment also in the 21 st century.

This paper, therefore, aims to look into the present condition and issues of social enterprises whose policies have brought significant effects in Korea in just 8 years, as well as policy issues for the development of sustainable social enterprises.

\section{Materials and Methods}

This paper is intended to research the recent status of social enterprises in Korea and analyze their issues. In particular, this paper aims to diagnose the causes of the issues generated in the course of the implementation of social enterprise policies, along with subsequent policy alternatives. The data used in the analysis is primarily based on existing studies and analysis data.

In addition, this paper allows the use of publicized data by the government, as well as the internal data analyzed and evaluated in the Korea Social Enterprise Promotion Agency to indicate the recent status of the social enterprise policies being evaluated as a social enterprise innovation, the driving force behind remarkable achievements, emerging issues and sustainable development in the future.

\section{Certification Status of Social Enterprise}

To be a social enterprise, a corporation or firm should provide job opportunities or social services to the vulnerable, or perform economic activities while in pursuit of social purposes such as public interest for the community. This requires essential conditions such as public interest that creates a social value as well as the formal requirements for a certification by the Minister of Employment and Labor according to the Social Enterprise Promotion Act. The definition of a social enterprise as well as its legal requirements, as stated previously, vary from country to country and its historic backgrounds are different.

By the end of 2007, the formal activities of Korean social enterprises began, as 50 companies received certifications from the government. As shown in Table 1, social enterprises had shown a rapid annual growth in number since a social enterprise was first certified in late 2007 , indicating that by the end of 20141,251 companies across the country received a certification to keep their businesses in operation. The average annual growth is $63.5 \%$ (SERF, 2014).

In addition, preliminary social enterprises certified preliminarily by local governments to incubate social enterprises also showed over 10 times more than the 2007 figure. Employment for the vulnerable who find it relatively hard to have job opportunities also rises from the original number of 1400 to 15,000 in 2014 , displaying more than 10 times increase. These results point out that job creation effect alone emerged by social enterprise policies pushed in Korea for the past 8 years generates about 28,000, which records an employment growth over 10 times higher than 2007.

These certification programs consist of five types: (i) a job-offering type for the vulnerable according to the purposes of a social enterprise, (ii) a type of social service provision for the vulnerable, (iii) a combination of the previous two types, (iv) a contribution type for improvement in the quality of community life and (v) another combination type. They are operated by way of government reviews, according to the purposes and requirements of the applicant companies.

Looking at a certified social enterprise by type as shown in Table 2, an enterprise with a type of social job provision takes up the absolute majority with 867 , social service provisions having 61 , community contributions owning 155 and other combined type with 146.

Looking at the distribution by organization type regarding social enterprises, the type of commercial law firms takes up the most percent with $40.4 \%$, the corporation of civil law $25.6 \%$, the not-for-profit organization and social welfare corporation also owning 19.3 and $11.9 \%$ respectively, which accounts for about $1 / 3$ of social enterprises (KED, 2011). 
Table 1. Social enterprise certification and employment status

\begin{tabular}{|c|c|c|c|c|c|c|c|c|}
\hline & 2007 & 2008 & 2009 & 2010 & 2011 & 2012 & 2013 & 2014.12 \\
\hline \multirow{2}{*}{ Certified enterprise (Number) Growth Rate (\%) } & 50 & 208 & 285 & 501 & 644 & 774 & 1,012 & 1,251 \\
\hline & 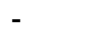 & 316 & 37 & 75.8 & 28.5 & 20.2 & 30.7 & 23.6 \\
\hline Preliminary certified enterprise (Number) & 396 & 602 & 646 & 961 & 1,260 & 1,425 & 1,463 & 1,466 \\
\hline Number of people in vulnerable employment (Number) & 1,403 & 4,832 & 6,467 & 8,227 & 10,018 & 11,091 & 13,619 & 15,815 \\
\hline Total employment of social enterprise (Number) & 2,539 & 8,329 & 11,150 & 13,443 & 16,319 & 18,297 & 24,048 & 27,923 \\
\hline
\end{tabular}

Notes: (1) A preliminary social enterprise is certified by a local government. (2) Year-end cumulative sum

Source: KSEPA (2014b), Abstract of a Social Enterprise

Table 2. Certification status by type

\begin{tabular}{|c|c|c|c|c|c|}
\hline & $\begin{array}{l}\text { Job } \\
\text { offering type }\end{array}$ & $\begin{array}{l}\text { Type of social } \\
\text { service provision }\end{array}$ & $\begin{array}{l}\text { Combined } \\
\text { type }\end{array}$ & $\begin{array}{l}\text { Community } \\
\text { contribution type }\end{array}$ & $\begin{array}{l}\text { Other } \\
\text { type }\end{array}$ \\
\hline Number of certified enterprises & 867 & 61 & 22 & 155 & 146 \\
\hline
\end{tabular}

One can figure out through these findings that a number of social enterprises in Korea received certifications in a short period of time 8 years and they are devoting themselves to providing social services to the vulnerable, creating job opportunities and economic activities known as the unique business objective. In other words, it is possible to say that the policies regarding the supporting and incubating of social enterprises pushed by the Korean government are highly effective. These outcomes may be evaluated to be a remarkable growth found nowhere else at any corner of the world.

\section{Support Programs for Social Enterprises}

The support program for social enterprises can be divided into the direct support and indirect support. The direct support is provided only to an enterprise that satisfies requirements based on the Social Enterprise Promotion Act for implementing policies. The indirect support, on the other hand, refers to backing the social enterprise market ecology and is intended to build a business-friendly ecosystem where management environment for enterprise management and profit creation can be improved and startup assistance and management renovation for social enterprises by incubating social entrepreneurs can be achieved (Kim and Yoon, 2012).

The support program for social enterprises is detailed in Table 3. Firstly, the direct support is grounded on the Social Enterprise Promotion Act. It includes the following: (i) Supporting labor cost (including professional personnel), (ii) supporting business development costs, (iii) supporting social insurance fees, (iv) supporting tax benefits such as corporate tax and income tax and (v) supporting facility costs.

Secondly, the indirect support deals with establishing networks by region and type of business, expert networks and pro bono, aiming at incubating and supporting social entrepreneurs. In addition, programs designed for incubating social entrepreneurs include social entrepreneur academies, business education and business support through social venture competition.

The government is also providing programs designed for support, such as assistance with business development costs, management consulting, social entrepreneur academy business and creating fund of funds, in order for preliminary social enterprises to incubate social enterprises as the pre-designated stage of a social enterprise. These multiple policy tools are used to implement many support programs to extend job creation opportunities and strengthen socio-economic independence (MEL, 2013).

\section{Roles and Results of a Social Enterprise}

The above mentioned social enterprise is certified by the government and its activities are performed through various support programs. In other words, a social enterprise primarily pursues social objectives while creating profits by the production and sales of goods and services. What is more, the social enterprise also carries out simultaneously such purposes as job creation for the vulnerable, social service provision, the resolution of social problems and regional integration. Therefore, the role of a social enterprise is significantly different from existing conventional firms in pursuit of profit seeking activities.

While conventional firms seek profits, social enterprises play two roles-the realization of social values and the realization economic values for achieving public interests. Of the two, Fig. 1 shows the ongoing roles of a social enterprise, such as providing sustainable job opportunities, renovated public services through service expansion, investment activation through community integration and local economic development, corporate social contribution activities and establishing spontaneous market order by creating ethical consumerism.

Implementation of a social enterprise has led to the following performances: Firstly, it produced job creation effect by increasing social enterprises. As the number of certified social enterprise has increased, it has provided about 27,000 jobs. This has also been served as an opportunity to increase the level of satisfaction through income security for employees, improve welfare such as through registering for four major insurance programs and provide a higher quality of life through reinforcing the social security net. In particular, it plays a significant role in providing stable job opportunities for the vulnerable (KLI, 2014). 
Table 3. Support programs for social enterprises

\begin{tabular}{|c|c|c|}
\hline Support programs & & Support details \\
\hline & Labor cost & Labor costs for participation in social work business (Minimum wage level) \\
\hline & $\begin{array}{l}\text { Labor costs for } \\
\text { professional personnel }\end{array}$ & $\begin{array}{l}\text { Labor costs for employing professional personnel } \\
\text { (within the limit of } 2 \text { million won) }\end{array}$ \\
\hline & Social development expenses & $\begin{array}{l}\text { Business expenses for technological development } \\
\text { (within the limit of } 70 \text { million won) }\end{array}$ \\
\hline Direct & Management support & $\begin{array}{l}\text { Management consulting for management, tax business, labor and accounting } \\
\text { (within the limit of } 3.3 \text { million won to } 20 \text { million won) }\end{array}$ \\
\hline \multirow[t]{4}{*}{ Support } & Social insurance fees & Partial support of four employer-paid major insurances ( 91,000 won per person) \\
\hline & Tax benefits & $\begin{array}{l}50 \% \text { reduction on corporate tax, income tax, acquisition tax and license tax } \\
\text { Admits donations to social enterprises as designated donation }\end{array}$ \\
\hline & Facility cost & Loans (micro-financing, policy fund for small and medium enterprises) \\
\hline & Fund of funds & $\begin{array}{l}\text { Creates fund through the Ministry of Employment and Labor and private financing } \\
\text { ( } 4 \text { billion won in 2012) }\end{array}$ \\
\hline Indirect & Public procurement system & Recommends preferred purchasing of social enterprise goods or services \\
\hline Support & Market exploring & Builds and operates online merchandise introduction site and a joint market \\
\hline
\end{tabular}

Source: Shon (2014), Issues and Improvement Programs in Social Enterprise Support System, National Assembly Research Service (NARS), Field Report, No.29.
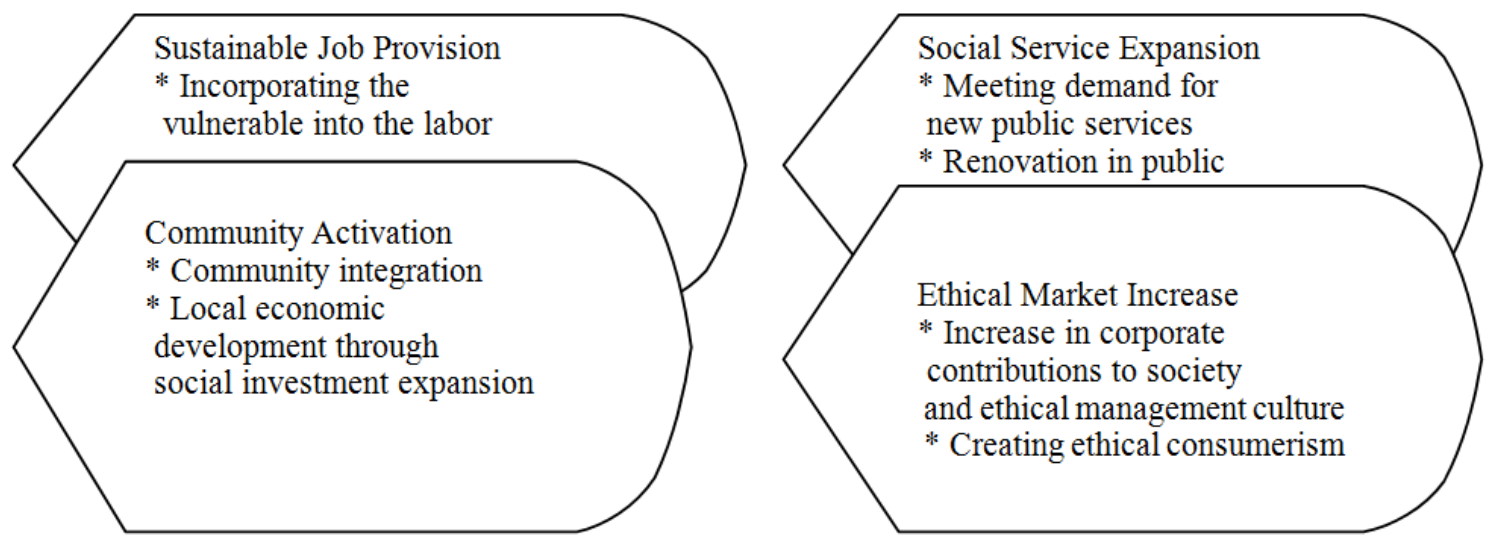

Fig. 1. Roles of a social enterprise Source: KSEPA (2014b), abstract of a social enterprise

Secondly, various support programs have been introduced through incubating government-led social enterprises at the initial stage. They built the opportunity to make the link between the local government and private organization more activated, as well as to maximize effects of support by region, sector and business as conglomerates have participated more broadly in the social enterprise sector (KSEPA, 2014a). These performances are also promoting the fostering of creative-minded social entrepreneurs who are able to implement a leading role in a social enterprise sector (Kim and Yoon, 2012).

Thirdly, it has constructed the public-private support system and also generated an increase in specialized businesses and brand business by local government and central governmental agency. Its activities have been growing by establishing and supporting social enterprises of the private sector, such as NGO, the religious world and conglomerates and it also has built an opportunity to bring together private sector capabilities (SERF, 2014).

\section{Emergence of Issues}

Faced with the economic crisis in late 1997 so-called an IMF financial crisis, the Korean government pushed social enterprise policies which have made economic achievements such as job creation for the economically vulnerable class, income security and providing many social services. The following are general issues in terms of the promotion of social enterprises and support programs led proactively by the government.

First, it laid too much emphasis on the quantitative expansion in its operation with a focus on excessive job creation effort, while being negligent in quality growth. That is, this caused the quality aspects such as independence and sustainability of social enterprises to be put behind the quantitative growth (IMC, 2012). 
Second, standardized support without considering diversity is an issue. Social enterprises come in a wide variety of businesses and sectors. In spite of different types in pursuit of social values, the government-led programs remained in the simple and standardized level with respect to investigation into the support enterprise, how to provide support funds, post-management and assessment system (MEL, 2013).

Third, there was a lock of creating the spontaneous ecosystem of social enterprises. In other words, according to the assessment from professionals, the importance of social enterprises is on the rise, but supporting labor costs takes a large portion according to an increase of small-size social enterprises. What is more, the programs experienced a failure in building environments for market extension friendly to social enterprises and recognition, leaving a large number of social enterprises dependent on the government (Shon, 2014).

Fourth, the fiscal cliff was caused by supporting temporary labor costs. That is, relying too much on temporarily-supported labor costs brings the canceling of employment after government support is terminated, or budget waste is taking place due to the lack of postmanagement. The controversy of so-called wasting money makes side effects on government intervention or moral hazard appear (SN, 2011).

Fifth, experts say that the programs were operated under too restrictive use by putting a limit in the usage of business development expenses and overly generous distribution of government budget. Business development expenses are outlined to be assisted up to 100 million won per year, but in 2012 a budget amount of 17.5 billion won for business development expenses was provided to 1,246 companies, making an average support fund of merely 14 million won per company (KCCSE, 2014).

Sixth, it turns out that the programs faced the lack of various education and training initiatives as well as the capabilities of supporting organizations by region due to the shortage of professional personnel. Moreover, the shortage of capable professional personnel brought a failure in providing no appropriate support for on-site demand by business and sector, resulting in keeping professionalism from being built due to the operational vacuum ( 2 months) caused by frequent replacement in selecting supporting organizations and the lack of continuity of business (IMC, 2012).

Seventh, while net profits loss of certified enterprises is increasing compared to 2012, but 635 businesses report net profits and the other half shows net operating loss. Labor productivity represented by sales per capita is on the continual rise, resulting in the lack of competitiveness as a productivity growth factor (KLI, 2014).

The above issues are factors that work as an impediment to the long-term development of social enterprises in Korea. One can see social enterprises in Korea have achieved development through the government proactively introducing a new system. Now that the government also did not set up the foundation for independent development in the market, some side effects and problems were expected. It is necessary to work on improvements of policy issues for long-term, sustainable development of social enterprises in the future.

\section{Discussion of the Results}

Social enterprises in Korea did not appear spontaneously in the market, but came into effect in line with government-led policy objectives such as job creation and profit creation through incubating social enterprises. Europe and the U.S. where social enterprises began and developed are led by market rather than the government in their social enterprises policies. Conversely, Korean government takes the lead in providing certifications to businesses with certain qualifications and such certification system serves as an opportunity to trust businesses in the market which is therefore bringing substantial effects also to economic activities.

In other words, government's certification system for social enterprises is evaluated to have greatly influenced incubation and development of social enterprises. Social enterprise policies in Korea have taken considerable short-term effects, along with an adjusted long-term goal of establishing the instantaneous ecosystem in the market. In addition, they are intended to motive the full practice of creative enterpreneurship through incubating social enterpreneurs.

In this study, the effects of social enterprise policies have led to the following results. Firstly, the job creation laid too much emphasis on the quantitative expansion while being negligent in quality growth. Standardized support without considering diversity in individual fields came up.

Secondly, there was a lock of creating the spontaneous ecosystem of social enterprises. That is, there is a growing criticism that the policies experienced a failure in building environments for market extension friendly to social enterprises and recognition, leaving a large number of social enterprises dependent on the government.

Thirdly, it is pointed out that the fiscal cliff was caused by supporting temporary labor costs. Namely, the canceling of employment takes place after government support is terminated, or budget waste is taking place due to the lack of post-management.

Fourthly, government supports are operated under too restrictive use by fair distribution of government budget. It turns out that the shortage of professional manpower results in the lack of competitiveness needed for growth in productivity.

\section{Policy Issues for Sustainable Development}

The government is carrying out new implementation plans with a focus on improving the above mentioned issues. In addition, the trends of declining birthrate and 
aging society are definitely distinctive of advanced countries according to the change in the global economic environment. Korea is not an exception and is facing the same trends. Moreover, expectations are arising as to the role of a social enterprise in solutions to the demand for future social services and employment issues. In particular, the role of a social enterprise in the local community is most significant.

Thereby, government-led policies are intended to find a new type of social enterprise model in a variety of sectors. This would continue to achieve the activation of a socioeconomic organization that simultaneously realizes job creation and social value. Listed below are the basic directions for system supplementation, on the support system of a social enterprise and for the enhancement of the independence of a social enterprise, as policy issues for the sustainable development of future social enterprises (MEL, 2013).

\section{Job Creation through Social Enterprises}

A new type of social enterprise is to be found and incubated in various sectors other than the vulnerable. In addition, job creation and post-management are to be continually performed by strengthening employment and startup assistance by social class, such as the youth, elderly and women and by actively discovering job opportunities in the social service sector.
Opportunities for the youth's actual business startup are to be provided so that they come up with creative ideas through social venture competitions and social enterprise training programs by stages, along with social entrepreneurship leader training and field experience mentoring services (Kim et al., 2014). For the elderly, on the other hand, an expansion of business startup and employment opportunities using experience and knowledge is to be considered, along with the create of jobs suited for people in their 50 and $60 \mathrm{~s}$ through specialized business startup programs, in possible association with senior job placement project. For women, job creation is to be led by pinpointing womenfriendly sectors, such as school lunch workers, childcare helpers, housekeepers and nursing as a social enterprise.

\section{Establishing the Ecosystem of a Social Enterprise}

To activate the ecosystem of a social enterprise, the existing Social Enterprise Promotion Act is to be expanded and reorganized into (tentatively called) Law on Social Enterprise Promotion and Support, in order to strengthen a functional linkage between similar businesses and also simplify procedures for certification requirements of a similar organization. A support system is prepared for the operation of an integrated coordinating organization committed for the coordination between similar policies and the interministerial collaborative task. Refer to Fig. 2 (Kim, 2011).

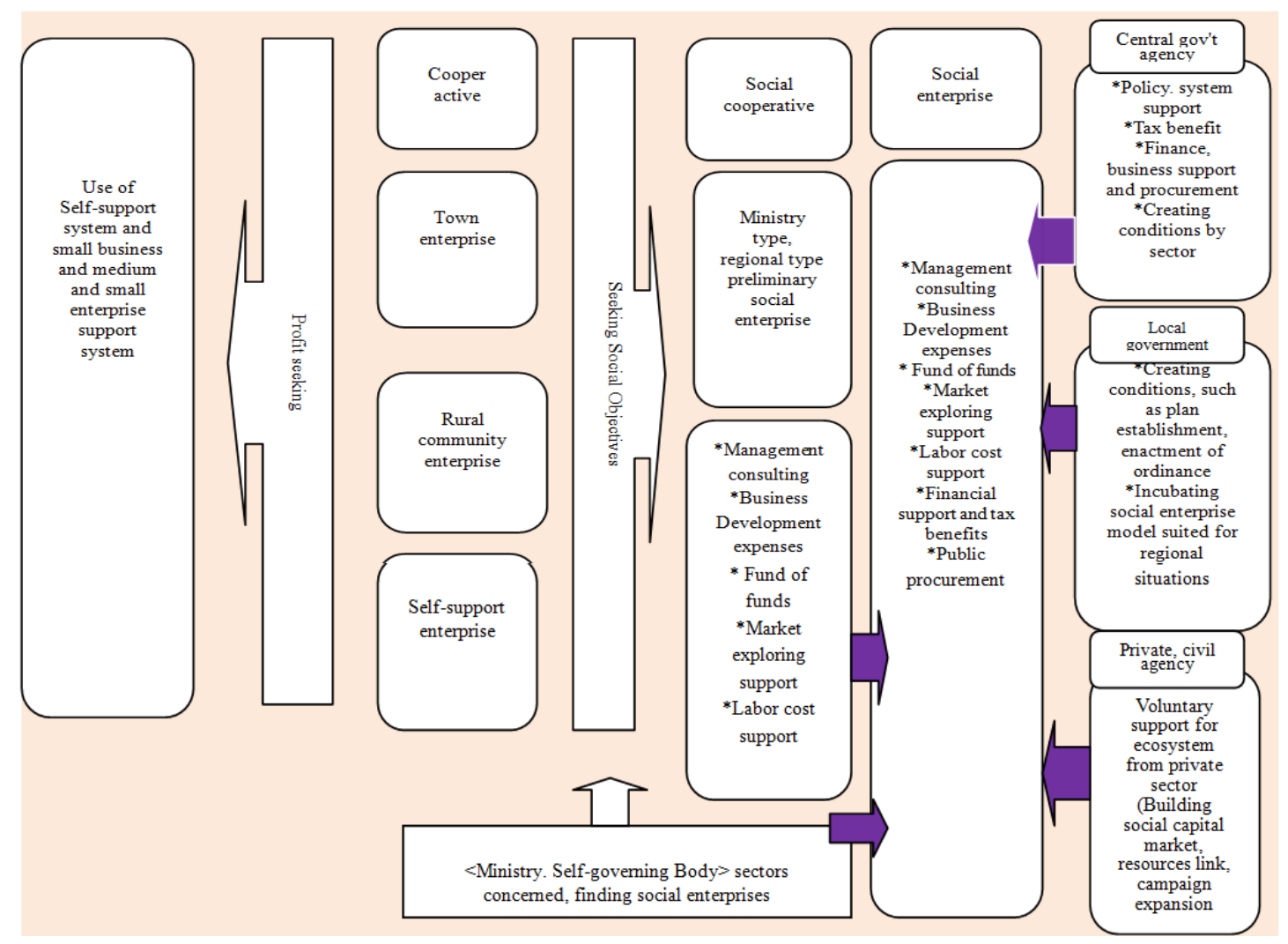

Fig. 2. Socio-economic support system Source: MEL (2013), implementation plans for social enterprise activation 
Incentives are provided to excellent social enterprises by establishing an evaluation basis, such as an index development that can measure and evaluate social performances through operating effective support system between similar businesses and reinforcing capabilities and infrastructure of a supporting organization.

\section{Support System Reorganization}

First, direct support methods for labor costs are improved. That is, to reduce the impact from terminating support for social enterprises, workers are promoted to work on a long-term basis to reduce the support ratio, provide a focused support to professional personnel in technological development and expand the support period to prompt social enterprise activities.

Second, the indirect support is expanded for selfsustaining independence. In other words, support programs include expansion of fund channel of a social enterprise for enhancing competitiveness such as business development and $R \& D$ assistance, establishing the procurement system friendly to social enterprises and supporting more active purchases of social enterprise products.

Third, the linkage and collaboration between private and community are established. This means to create the ecosystem in a virtuous cycle that connects to the community providing solutions to a social issue such as polarization in the market, by linking conglomerates' social contribution activities to supporting social enterprises.

After taking everything into consideration, the continuous development of a social enterprise requires, most of all, policy improvements on the issues indicated above. It is essential to establish an ecosystem capable of achieving profit creation by means of the activities of a self-sustaining social enterprise in the market. So far, a number of social enterprises have been created and developed thanks to the government's support policies. Support programs are supposed to face limitations from now on due to their unique nature. That being said, it is important to incubate social enterprises as future directions for development and objectives. But, it is also necessary to convert policy coordination that nurtures independence for nurtured social enterprises to be able to perform economic activities in a proper manner.

\section{Conclusion}

To see social enterprises develop sustainably, first of all, the objectives of policies newly planned and pushed by the government should be achieved. Second of all, the crucial point is to expand the value of a social enterprise and strengthen independence. This refers to establishing the economic order to realize the goal of social enterprises-the pursuit of private profits and public interests-through the social enterprises nurtured up to the present standing on fair market competitiveness.

\section{Acknowledgement}

This research was supported by the Konkuk University research program.

\section{Funding Information}

This research was supported by the 2014 Konkuk University research grants.

\section{Author' Contributions}

Both the authors have equally contributed to this manuscript.

\section{Ethics}

The authors confirm that this work is original and has not been published elsewhere.

\section{References}

Shon, E.C., 2014. Issues and improvement programs in social enterprise support system. National Assembly Research Service.

Kim, E.S., 2011. Roles of social enterprise and government. Issues and Diagnosis, Gyeonggi Research Institute.

IMC, 2012. The 2nd basic plans for promoting social enterprises. Inter-Ministerial Collaboration.

KCCSE, 2014. Korea central council of social enterprise. http://www.ikose.or.kr

KSEPA, 2014a. Abstract of social enterprises. KSEPA.

OECD, 1997. The emergence of social enterprise. OECD.

SN, 2011. Social enterprises have controversy of wasting money. Saejeonbuk News.

SERF, 2014. Social enterprise revitalization forum. http://www.besene.org

KED, 2011. New experiment in social enterprise for 4 years. The Korea Economic Daily.

KSEPA, 2014b. The Korea Social Enterprise Promotion Agency. http://www.socialenterprise.or.kr/index.do

KLI, 2014. Social enterprise performance analysis of the 2013. The Korean Labor Institute.

MEL, 2013. Revitalization action plan for social enterprises. The Ministry of Employment and Labor.

Kim, Y.D. and S. Yoon, 2012. Current status and policy implications for fostering social entrepreneur. Am. J. Econom. Bus. Administration., 4: 155-165. DOI: 10.3844/ajebasp.2012.155.165

Kim, Y.D., S. Yoon and H.G. Kim, 2014. An economic perspective and policy implication for social enterprise. Am. J. Applied Sci., 11: 406-413. DOI: 10.3844 /ajassp.2014.406.413 